\title{
Co-designing Cards on Social Issues for Creating Educational Games
}

\author{
Christina Myers \\ The Open University \\ Milton Keynes, UK \\ christina.myers@open.ac.uk
}

\author{
Lara S. G. Piccolo \\ The Open University \\ Milton Keynes, UK \\ lara.piccolo@open.ac.uk
}

\author{
Trevor Collins \\ The Open University \\ Milton Keynes, UK \\ trevor.collins@open.ac.uk
}

\begin{abstract}
This paper presents a participatory methodology to design cards on social issues with the purpose to democratise knowledge among co-designers on the learning content of educational games. Situated on the topic of everyday sexism, the methodology has been developed through an iterative process involving two collaborative workshops, two iterations of card design and a feedback survey. Extracting findings from the workshops and the feedback gathered on the codesigned cards, this paper presents insights that could be used to inform similar studies using cards to inspire and foster reflection on social issues.
\end{abstract}

Educational game design. Design cards. Everyday Sexism. Participatory Design. Democratisation of Knowledge.

\section{INTRODUCTION}

Applying co-design to educational games has the potential to generate more effective educational outcomes. Yet, it represents a challenge as best practices to co-design such games, which require technical, conceptual and educational skills, still have to be defined (Carvalho et al., 2015; DeSmet et al., 2016). Most of the participatory models to design educational games are founded on educational theories and game design (see for example: Amory, 2007; Arnab et al., 2015). Some more recent models, though, have also included domain experts to define the learning content of the educational game (De Jans et al., 2017). In scenarios where the co-designers are not equally experienced with the educational game domain or with the design process, tools to facilitate the design and maximize educational outcomes may be required.

Within the Human-Computer Interaction $(\mathrm{HCl})$ literature, cards have been pointed out as a tool with the potential to democratise knowledge and to support collaborative design of realistic and innovative projects. Chow et al. (2016) have argued that cards should "capture a wide range of situations and personalities" (p.91) to inspire designers with concepts that are familiar or new to them. For supporting the design of cards, Kensing and Greenbaum (2012) proposed some participatory design principles for transcribing diversified experiences and knowledge to the cards.

Using participatory approaches to design cards has been described as having the potential to enable more engaging and effective design experiences and results (Chow et al., 2016; Golembewski and Selby, 2010; Halskov and Dalsgärd, 2006). The literature, however, shows limited number of studies presenting methodologies to this end.

This work-in-progress focuses on the development of a methodology to co-design cards on a social issue. In the context of this research, such cards refer to the learning content of educational games that will also be co-designed in the future. The cards aim at democratising knowledge, inspiring and triggering reflection among co-designers with different levels of understanding on the social issue.

The methodology has been developed through an iterative process consisting of collaborative workshops, sequential reviews and iterations of card designs, and a summative feedback survey. Although instantiated on the social issue of everyday sexism, it is expected that the proposed methodology can be applied to similar studies aiming at co-designing cards for creating educational games on different social topics that affect people's everyday lives.

In the next section, setting the scene for the study, some key points from the literature on everyday sexism are introduced, followed by a review of cardbased tools to support design. Section 3 describes the methodology to co-design a set of domain cards on a social topic, which leads to further discussions on the results and future work in section 4 .

\section{BACKGROUND}

This section starts by contextualising this research with an overview of everyday sexism, then turns to present a literature review on card-based tools. 


\subsection{Everyday sexism as a social issue}

Everyday sexism rests on the concept that sexism is either faced or reproduced on a daily basis but is rarely noticed (Barreto et al., 2009; Becker and Swim, 2011). Identifying everyday sexism and its different forms, empathising with other people's experiences, and reflecting on them are seen as possible ways to contribute to gender equality (Becker and Swim, 2011; Zawadzki et al., 2013). More particularly, using everyday experiences to reflect on them is an important stepping stone in the history of feminism (Freedman, 2014; Sarachild, 1968).

\subsection{Literature review on card-based tools}

In the $\mathrm{HCl}$ domain, cards have been applied in a range of contexts, with considerable distinction in terms of purpose, content, and target audience's expertise. Naming a few, Vines et al. (2012) showed positive results in using cards to design banking technologies for and with people with limited familiarity with the topic. Chow et al. (2016) applied cards to create innovative ways to teach mathematics; Lucero and Arrasvuori (2013) to support the design for playfulness; both Golembewski and Selby (2010) and Roubira (2008) used cards as an inspiration tool to define and explore preliminary design ideas; and Halskov and Dalsgärd (2006) to explore how to apply technology to concepts from domain studies.

In Deng et al. (2014), the cards were intended to make knowledge on tangible learning games accessible by translating "lengthy, dense, and jargon laden (body of literature) to design practice" (p.1). Wetzel et al. (2016) presented sets of cards throughout the design process to create mixed reality games. Distinct sets of cards covered different stages of the design process, such as cards with abstract images applied at the ideation phase. In the study presented by Flanagan et al. (2011), the cards were aimed at engaging diverse audiences to facilitate the creation of game ideas prioritising human values. One of their Challenge cards (i.e. the social issue to be solved) targeted sexism and was illustrated as, "Description: Stereotype of a discrimination based on sexual roles. Strategy: Education, awareness, legislation" (Flanagan, 2010, p.1).

The structure and content of the cards are subjects of discussion in the literature, including textual elements as descriptions, examples, reflective questions or lived experiences and illustrations. Deng et al. (2014) evaluated different cards' elements with groups of both experienced and inexperienced designers on the topics presented on the cards and found out that the inexperienced ones tended to ignore the cards and requested more textual information to understand and be able to use the cards.

The impact of reflective questions in the cards has also been debated. Chow et al. (2016) used questions to encourage reflection on everyday experiences related to mathematics, arguing that it could increase engagement among users. Vines et al. (2012) included questions on their cards for the users to answer and found that the responses received were superior in quality when compared with typical responses to written questionnaires.

Reports of lived experiences were also found in some of the cards. The evaluation by Lucero and Arrasvuori (2013) revealed that using real-life experiences on the cards could be more understandable and inspiring than a definition of concept. The study of Vines et al. (2012) also used quotations based on real experiences and found positive outcomes in terms of creating engagement, stating that quotations invited the users of the cards to learn and empathise with other people's experiences.

Illustrations are arguably a source of inspiration and an important element in the aesthetics of cards (Lucero and Arrasvuori, 2013; Wetzel et al., 2016). A study compared PLEX Cards, which contain a definition and an informative illustration; and DIXIT Cards, which represent abstract illustrations, and found similar results in terms of numbers of ideas generated (Kwiatkowska et al., 2014). However, both Chow et al. (2016) and Deng et al. (2014) found different results in favour of illustrations representing straight-forward and informative concepts.

Amongst the literature reviewed, Golembewski and Selby (2010) was the only study that presented a methodology for co-designing cards. The cards consisted of a single word and a descriptive icon classified accordingly to the domain of the project undertaken. This study considered the formulation of initial ideas and avenues for exploration a fundamental part of the design process and invited co-designers to define the conceptual space of their own project by co-designing cards.

\section{METHODOLOGY}

The methodology proposed differs considerably in its form, users and outcomes from the methodology presented by Golembewski and Selby (2010), in which the cards were co-designed and used by the same group of designers. Instead, the cards codesigned in this study intend to be interpretable and usable by other groups of designers. In line with Vines et al. (2012) and Deng et al. (2014), the set of co-designed cards aims to democratise knowledge in an easy-to-understand and inspiring manner among people with different background. 
Referring to the structure, Golembewski and Selby (2010) co-created cards composed by singular words and icons. As seen in the study of Deng et al. (2014), such a minimalist structure could limit the potential to promote reflection among the targeted audience of this study. Similarly, the cards created by Flanagan et al. (2011) risk to overgeneralise complex issues such as sexism, by illustrating it with a single definition.

\subsection{Overview}

To co-design the cards, we organised two workshops and an online survey. The first workshop involved 23 participants, 8 females and 15 males, while the second one had 4 males and 6 females. The workshops were held at a university lab involving researchers related or not with the topic, PhD students, and administration staff. As further described, some aspects of the first workshop were reviewed and informed a second collaborative workshop. The workshops' participants were organised in groups of 3 to 4 people, each group addressing different categories of everyday sexism. The seven categories of everyday sexism were: 'Benevolent Sexism', 'Sexist Language', 'Genderbased Harassment', 'Gender Stereotypes', 'Online Gender Discrimination', 'Feminism' and 'Downplaying Gender Discrimination'.

The workshops started with a 45 minutes exercise where the groups were asked to define keywords, illustrations and reflective questions on a category of everyday sexism. The participants were also asked to read, individually, 8 written lived experiences related to the same category of everyday sexism and select the 3 most representative ones in groups. The lived experiences were extracted from a website called everydaysexism.com where people shared their experiences on everyday sexism (Melville et al., 2017). Reflective questions aimed at triggering reflection by future card users who would not necessarily be aware on the issues. This exercise was supported by a template in an A3 paper that guided participants towards completing the tasks, and also invited them to add any sort of suggestion. After this exercise, each group had 10 minutes to provide feedback on the information generated by another group. The workshops were concluded with each group presenting their results to all participants in 5 minutes.

The outcome of the two collaborative workshops, including the filled A3 page, the feedback received and the transcription of the groups' presentation, informed the design of 7 cards, one for each category of everyday sexism. The cards were composed by a title, keywords, 3 lived experiences, an abstract image and 4 to 8 reflective questions. Once the cards were designed, an online feedback questionnaire was developed aiming at collecting people's perception on the cards' potential to inspire and trigger reflection on the specific category of everyday sexism. A total of 58 people, including workshop participants, provided feedback on a set of 3 or 4 cards each, resulting in at least 26 responses for each card. Based on this feedback, a second iteration of cards was created.

\subsection{Results}

The results are presented in two subsections; one on the workshop structure (3.2.1) and the findings of the feedback process (3.2.2).

\subsubsection{Revisions of collaborative workshops}

The template on the A3 page was refined between the workshops. The main difference was situated in the reflective question section. Several participants expressed that the task 'elaborate questions that would raise awareness on the category of everyday sexism to people not necessary aware of it', was difficult and that they were not satisfied with their results. Following the process of reflection presented by Wood Daudelin (1996), in the new version the first word of 4 questions were added as a visual prompt. The instruction was then, for example, to create a 'what question' targeting the problem identification. The second workshop showed improved results as the questions were more connected to the lived experiences and none of the 10 participants reported any difficulty to create reflective questions as a feedback. Figure 1 illustrates the final version of the template on the A3 page used in the second workshop.

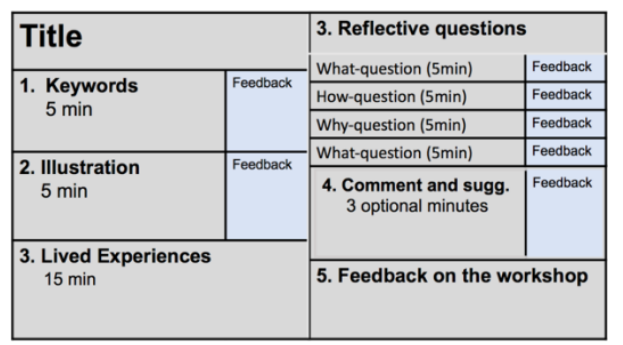

Figure 1: Final version of A3 Page template

The keyword, lived experiences and illustration sections were evaluated as being constructive exercises as the participants were engaged in critical discussions and the group responses were considered clear, informative and diversified. Several participants reported enjoying reading the "eye-opening" lived experiences. Figure 2 is an example of an generated illustration which describes a group discussions on the use of the word 'just' to identify scenarios where people could be downplaying gender discrimination.

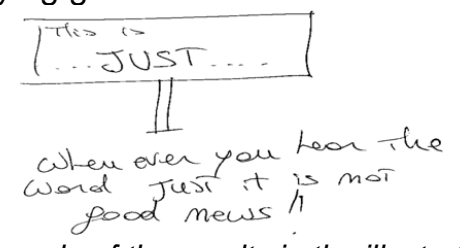

Figure 2: Example of the results in the illustration section 
To inform the cards design with the workshops outcomes, some lived experiences were slightly edited in order to make them shorter, and keywords were used with a hashtag to reinforce their symbolic meaning. In addition, based on the literature presented (Kwiatkowska et al., 2014; Wetzel et al., 2016), abstract illustrations were added to the cards while the content generated on the illustration section was used to complement the keywords and the reflective questions.

\subsubsection{Feedback survey}

A total of 58 people, 33 females and 25 males, responded to the survey of whom, 5 people $(8.6 \%)$ considered themselves experts on the topic of everyday sexism while 33 people $(56.9 \%)$ aware, 17 people $(29,3 \%)$ learners, 2 people $(3,4 \%)$ unaware and one person $(1,7 \%)$ indifferent. All the workshop participants were invited to respond to this survey. Firstly, the responses as a 6-point Likert scale to the question 'I find this card very clear and understandable' showed an average rating of 4.92 out of 6 , where the number 1 corresponded to 'Strongly disagree' and 6 to, 'Strongly agree'. Secondly, the responses on 'I find this card very inspiring and lead me to reflection on [category of everyday sexism]' was 5.57 out of 6 , on the same scale. The standard deviation for the first question was 1.13 and 1.14 for the second question, suggesting that the responses were not significantly dispersed over a wide range of values in any of these questions.

The next question was 'I find [card element] very useful to trigger my reflection on [category of everyday sexism]' and the potential responses ranked from 'Strongly agree' to 'Strongly disagree'. The average results on the cards were that $40 \%$ of the respondent agreed or strongly agreed on the keywords being very helpful; $91 \%$ on the lived experiences; $38 \%$ on the illustrations; $82 \%$ on the reflective questions and $77 \%$ on all elements together.

An open question requested feedback to improve each of the card separately, resulting in 147 suggestions. Most of the feedback aimed at making the images less abstract ( 21 entries), to simplify the reflective questions (20 entries), give more context to the keywords (14 entries), edit and shorten the lived experiences (11 entries) and limit the number of question to 4 per card (8 entries).

Based on the evaluation results, a new iteration of card was created, as depicted in Figure 3. The number of reflective questions was limited to 4 , the questions were made more concise, the lived experiences re-phrased towards shortening them to a maximum of 50 words and the keywords were made more explicit (e.g. \#ltsJust instead of \#Just). The abstract illustrations were also replaced by more informative illustrations reflecting the information gathered from the workshops and complemented by the transcription of the presentation of each group, as illustrated in Figure 3. The back of the card presented in Figure 3 contains four sequential questions; the first one being "What is the problem with downplaying sexism using words such as 'just' or 'only' (e.g. it's just a compliment)?".

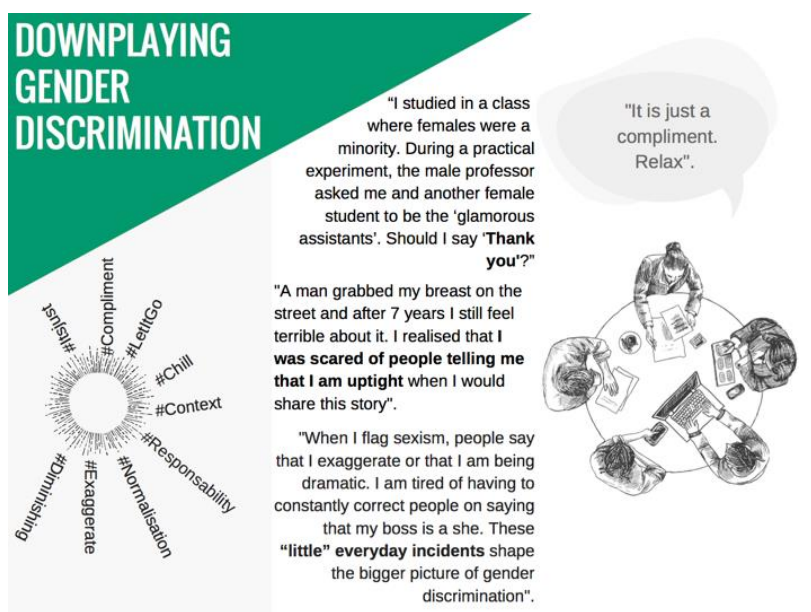

Figure 3: Second iteration of the front of the card category called 'Downplaying gender discrimination'

\section{CONCLUSIONS AND FUTURE STUDY}

This paper introduced an on-going work towards building a participative methodology for designing cards on social issues, which in the context of this research, will be used to define the learning content related to everyday sexism when co-designing educational games. Some preliminary results based on collected feedback are also presented, supporting the proposed methodology. The methodology provides guidance on how to structure collaborative workshops to define various cards elements, namely keywords, lived experiences, an illustration, and reflective questions. The design of these cards elements is supported by a template. We recommend to other studies aiming at similar objectives to use and adapt the template (Figure 1) to other social issue. Based on the feedback gathered, it is also recommended to limit the number of reflective questions to 4 while making them as concise as possible, to avoid using abstract illustrations, restraint the lived experiences to approximately 50 words and contextualise the keywords as much as possible. Future studies will address the application of the cards the co-design educational games on everyday sexism.

\section{REFERENCES}

Amory, A., 2007. Game Object Model Version II: A Theoretical Framework for Educational Game Development. Educ. Technol. Res. Dev. 55, 51-77. 
Arnab, S., Lim, T., Carvalho, M.B., Bellotti, F., Freitas, S., Louchart, S., Suttie, N., Berta, R., De Gloria, A., 2015. Mapping learning and game mechanics for serious games analysis. Br. J. Educ. Technol. 46, 391411.

Barreto, M., Ryan, M., Schmitt, M., 2009. The glass ceiling in the 21st century: Understanding barriers to gender equality.

Becker, J.C., Swim, J.K., 2011. Attention to Daily Encounters With Sexism as Way to Reduce Sexist Beliefs. Psychol. Women Q. 35, 227-242.

Carvalho, M.B., Bellotti, F., Berta, R., De Gloria, A., Sedano, C.I., Hauge, J.B., Hu, J., Rauterberg, M., 2015. An activity theorybased model for serious games analysis and conceptual design. Comput. Educ. 87, 166-181.

Chow, J., Kusoffsky, M., Kurti, A., 2016. From Abstract to Concrete: Telling Math Stories with Cards, in: Proceedings of the 14th Participatory Design Conference: Short Papers, Interactive Exhibitions, Workshops - Volume 2, PDC '16. ACM, New York, NY, USA, pp. 90-91.

De Jans, S., Van Geit, K., Cauberghe, V., Hudders, L., De Veirman, M., 2017. Using games to raise awareness: How to co-design serious mini-games?. Comput. Educ. 110, 77-87.

Deng, Y., Antle, A.N., Neustaedter, C., 2014. Tango cards. URL https://dl-acmorg.libezproxy.open.ac.uk/citation.cfm?doid $=2598510.2598601$.

DeSmet, A., Thompson, D., Baranowski, T., Palmeira, A., Verloigne, M., Bourdeaudhuij, I.D., 2016. Is Participatory Design Associated with the Effectiveness of Serious Digital Games for Healthy Lifestyle Promotion? A Meta-Analysis. J. Med. Internet Res. 18, e94.

Flanagan, M., 2010. Tiltfactor | Grow-A-Game. URL http://www.tiltfactor.org/game/grow-agame/.

Flanagan, M., Belman, J., Helen Nissenbaum, Diamond, J., 2011. Grow-A-Game: A Tool for Values Conscious Design and Analysis of Digital Games

Freedman, J., 2014. Reclaiming the Feminist Vision: Consciousness-Raising and Small Group Practice. McFarland \& Co, Jefferson, North Carolina.

Golembewski, M., Selby, M., 2010. Ideation Decks: A Card-Based Design Ideation Tool.

Halskov, K., Dalsgärd, P., 2006. Inspiration Card Workshops, in: Proceedings of the 6th Conference on Designing Interactive Systems, DIS '06. ACM, New York, NY, USA, pp. 2-11.
Kensing, F., Greenbaum, J., 2012. Heritage: Having a say. Routledge Int. Handb. Particip. Des. P21-36.

Kwiatkowska, J., Szóstek, A., Lamas, D., 2014. (Un)Structured Sources of Inspiration: Comparing the Effects of Game-like Cards and Design Cards on Creativity in Codesign Process, in: Proceedings of the 13th Participatory Design Conference: Research Papers - Volume 1, PDC '14. ACM, New York, NY, USA, pp. 31-39.

Lucero, A., Arrasvuori, J., 2013. The PLEX Cards and its techniques as sources of inspiration when designing for playfulness (PDF Download Available). URL https://www.researchgate.net/publication/2 64824212 The PLEX Cards and its tec hniques_as_sources_of_inspiration_when_ designing_for_playfulness.

Melville, S., Eccles, K., Yasseri, T., 2017. Semantic Map of Sexism: Topic Modelling of Everyday Sexism Project Entries.

Roubira, J.-L., 2008. Dixit. BoardGameGeek. URL https://boardgamegeek.com/boardgame/39 856/dixit.

Sarachild, 1968. Consciousness-Raising: A Radical Weapon'

Vines, J., Blythe, M., Lindsay, S., Dunphy, P., Monk, A., Olivier, P., 2012. Questionable Concepts: Critique As Resource for Designing with Eighty Somethings, in: Proceedings of the SIGCHI Conference on Human Factors in Computing Systems, CHI '12. ACM, New York, NY, USA, pp. 1169-1178.

Wetzel, R., Rodden, T., Benford, S., 2016. Developing Ideation Cards for Mixed Reality Game Design.

Wood Daudelin, M., 1996. Learning from experience through reflection. Organ. Dyn. 24, 36-48.

Zawadzki, M.J., Shields, S.A., Danube, C.L., Swim, J.K., 2013. Reducing the Endorsement of Sexism Using Experiential Learning: The Workshop Activity for Gender Equity Simulation (WAGES). Psychol. Women Q. 38, 75-92. 